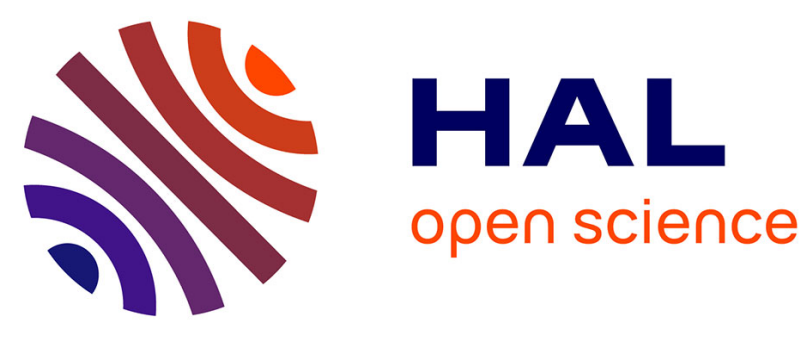

\title{
Intervertebral disc characterization by shear wave elastography: an in-vitro preliminary study
}

Claudio Vergari, Philippe Rouch, Guillaume Dubois, Dominique Bonneau, Jean Dubousset, Mickael Tanter, Jean-Luc Gennisson, Wafa Skalli

\section{To cite this version:}

Claudio Vergari, Philippe Rouch, Guillaume Dubois, Dominique Bonneau, Jean Dubousset, et al.. Intervertebral disc characterization by shear wave elastography: an in-vitro preliminary study. Proceeding of the IME Part H: Journal of Engineering in Medicine, 2014, pp.In Press. 10.1177/0954411914540279 . hal-01010870

\section{HAL Id: hal-01010870 \\ https://hal.science/hal-01010870}

Submitted on 20 Jun 2014

HAL is a multi-disciplinary open access archive for the deposit and dissemination of scientific research documents, whether they are published or not. The documents may come from teaching and research institutions in France or abroad, or from public or private research centers.
L'archive ouverte pluridisciplinaire HAL, est destinée au dépôt et à la diffusion de documents scientifiques de niveau recherche, publiés ou non, émanant des établissements d'enseignement et de recherche français ou étrangers, des laboratoires publics ou privés. 


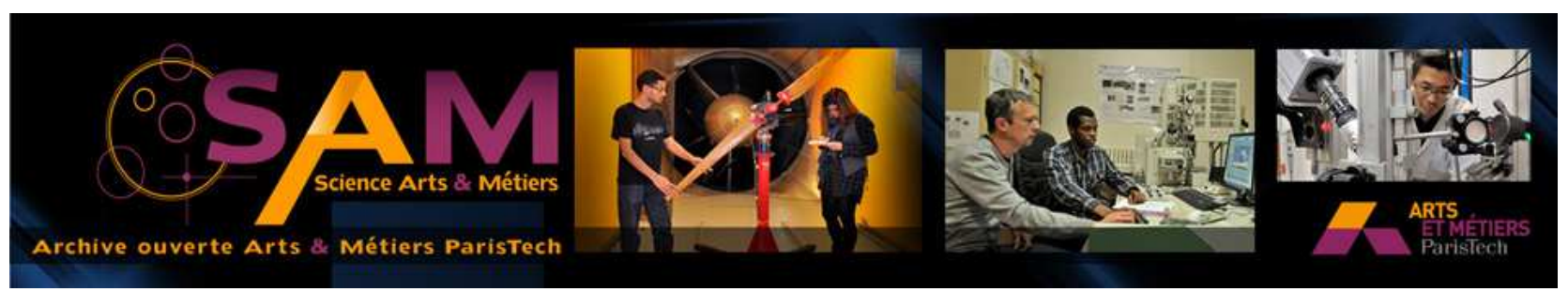

\section{Science Arts \& Métiers (SAM)}

is an open access repository that collects the work of Arts et Métiers ParisTech researchers and makes it freely available over the web where possible.

This is an author-deposited version published in: http://sam.ensam.eu

Handle ID: .http://hdl.handle.net/10985/8274

\section{To cite this version :}

Claudio VERGARI, Claudio VERGARI, Philippe ROUCH, Guillaume DUBOIS, Dominique BONNEAU, Jean DUBOUSSET, Mickael TANTER, Jean-Luc GENNISSON, Wafa SKALLI Intervertebral disc characterization by shear wave elastography: an in-vitro preliminary study Proceeding of the IME Part $\mathrm{H}$ : Journal of Engineering in Medicine p.In Press - 2014 


\title{
Intervertebral disc characterization by shear wave elastography: an in- vitro preliminary study
}

\author{
Claudio Vergari* ${ }^{1}$, Philippe Rouch ${ }^{1}$, Guillaume Dubois ${ }^{1}$, Dominique Bonneau ${ }^{1}$, Jean \\ Dubousset $^{1}$, Mickael Tanter ${ }^{2}$, Jean-Luc Gennisson ${ }^{2}$ and Wafa Skalli ${ }^{1}$
}

\begin{abstract}
Patient-specific numerical simulation of the spine is a useful tool both in clinic and research. While geometrical personalization of the spine is no more an issue, thanks to recent technological advances, non-invasive personalization of soft tissue's mechanical properties remains a challenge. Ultrasound elastography is a relatively recent measurement technique allowing the evaluation of soft tissue's elastic modulus through the measurement of shear wave speed (SWS). The aim of this study was to determine the feasibility of elastographic measurements in intervertebral disc (IVD). An in-vitro approach was chosen to test the hypothesis that SWS can be used to evaluate IVD mechanical properties and to assess measurement repeatability. Eleven oxtail IVDs were tested in compression to determine their stiffness and apparent elastic modulus at rest and at $400 \mathrm{~N}$. Elastographic measurements were performed in these two conditions and compared to these mechanical parameters. The protocol was repeated six times to determine elastographic measurement repeatability. Average SWS over all samples was $5.3 \pm 1.0 \mathrm{~m} / \mathrm{s}$, with a repeatability of $7 \%$ at rest and $4.6 \%$ at $400 \mathrm{~N}$; stiffness and apparent elastic modulus were $266.3 \pm 70.5$ $\mathrm{N} / \mathrm{mm}$ and $5.4 \pm 1.1 \mathrm{MPa}$ at rest, respectively, while at $400 \mathrm{~N}$ they were $781.0 \pm 153.8$ $\mathrm{N} / \mathrm{mm}$ and $13.2 \pm 2.4 \mathrm{MPa}$. Correlations were found between elastographic measurements and IVD mechanical properties; these preliminary results are promising for further in-vivo application.
\end{abstract}

\section{Keywords:}

Spine; intervertebral disc; soft tissue; stiffness; elastic modulus; quantitative ultrasound; 


\section{Introduction}

Numerical simulation of human spine or spinal segments mechanical behaviour is a useful tool in a number of applications, both in clinic and research. For instance, they allow planning of surgical procedures [1-3], studying the aetiology, progression and effects of spinal deformities [4, 5], intervertebral disc (IVD) degeneration [6-8] or crash injuries [9].

Patient-specific modelling is gaining more attention because of its potential role in improving diagnosis and optimizing treatments [10]. Developments in imaging modalities allow personalization of spine and ribcage geometrical properties [11-15]. However, material properties are usually assigned using previously measured values, often through invitro testing. In-vivo personalization of tissues mechanical properties remains a major challenge.

Soft tissues, and IVDs in particular, play an important role in the mechanical behaviour of the spine, especially in the presence of diseases that alter their properties [16, 17]. Spinal flexibility is often assessed by traction or bending tests before surgical treatment of scoliosis [18, 19]; this approach has been used to develop inverse methods to estimate intervertebral stiffness [20-22]. These methods, however, only provide the stiffness distribution along the spine, and they usually require the acquisition of several radiographic images which induce a radiation dose that has to be justified in clinical routine. More invasive measuring techniques are also being explored [23], but they can only be applied during surgery. Direct and non-invasive measurement techniques to assess spine flexibility are still lacking, although preliminary results have been reported in IVD mechanical characterization with magnetic resonance imaging [24-27].

Such non-invasive methods of mechanical characterization could also be relevant in vitro; mechanical testing is currently the gold standard to determine IVD material properties, but it usually relies on destructive testing [28, 29], which necessarily alter the continuity of the tissues, or on inverse schemes based on finite element models [30]. Alternative methods could also be used to obtain local mechanical properties of single IVD when mechanical testing is not possible or practical, for instance in instrumented functional units.

Ultrasound elastography has been a subject of research since the early 90s [31], but new quantitative real-time techniques have only recently been introduced in the clinical setting [32]. This non-invasive technique allows the evaluation of the tissue's elastic modulus through the measurement of shear wave speed (SWS) within the tissue; it has been successfully applied to assess several tissues, such as muscles [33], breasts [32, 34] and liver [35, 36], while preliminary work is being performed on several other soft tissues [37-39]. Ultrasound elastography seems a good candidate to assess IVD mechanical properties in vivo; its use, however, has previously been limited to relatively large (with respect to shear wave wavelength) and homogeneous organs, while the IVD is small, nonhomogeneous, anisotropic, and it is sandwiched between two bones (the vertebral bodies, which could cause artefacts due to wave interference or mode conversion). Therefore, the ability of SWS measurements to convey information on the tissue mechanical properties requires verification.

The feasibility of IVD mechanical characterization by elastography was explored in the present study by evaluating SWS measurement repeatability in the IVD and by testing the hypothesis that SWS can be used to evaluate IVD mechanical properties.

\section{Material and methods}

\section{Samples}

A bovine model was chosen to test the feasibility of IVD characterization by elastography. Eleven oxtails were included in this study; information on the animal's ages was not available. Stereoradiographic images (EOS system, EOS Imaging, Paris, France) of each oxtail were acquired (Figure 1) before freezing in sealed bags. Intact oxtails were slowly thawed at room temperature the night before each test; samples were prepared by isolating the first, 
second or third caudal segment (two vertebrae and the interposed disc) and by removing the that the vertebral bodies were aligned in order to minimize buckling during the subsequent

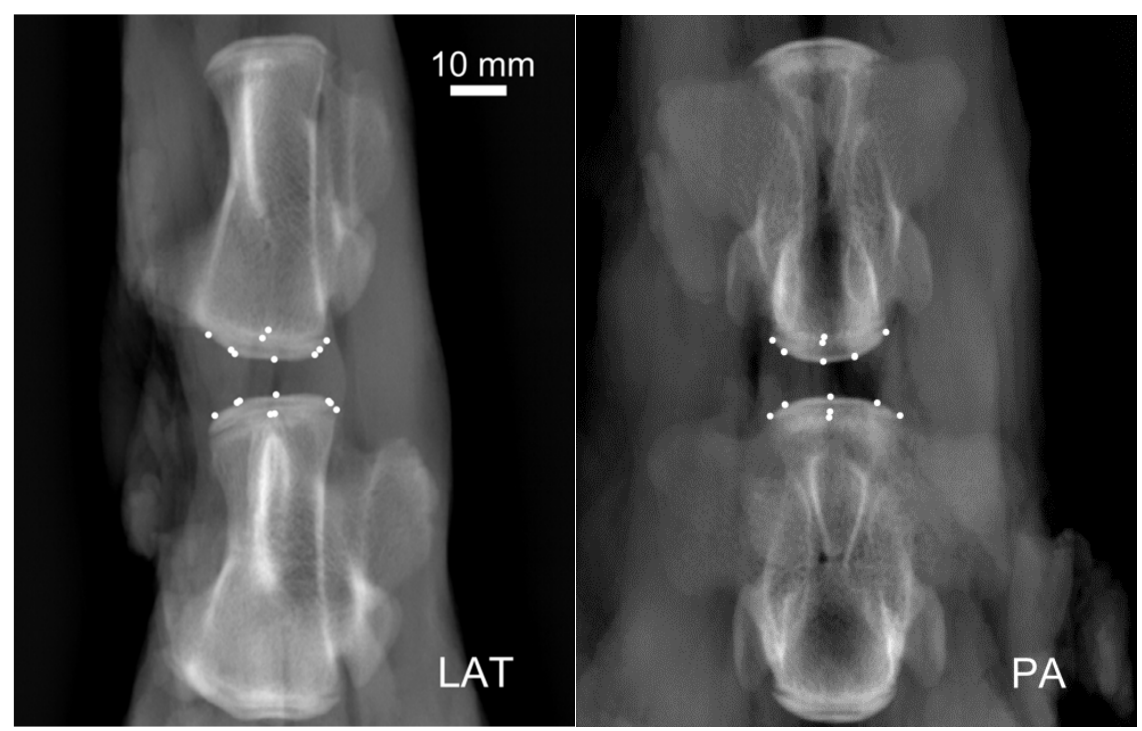

Figure 1 - Stereoradiographic images of an oxtail functional unit (two vertebras and the intervertebral disc); lateral (LAT) and postero-anterior (PA) view. Nine stereocorresponding points (white dots) were defined in both images to outline each vertebral endplate and evaluate intervertebral disc thickness and cross-sectional area.

soft tissues of the dorsal aspect (Figure 2). Soft tissues from the sample's ventral aspect were only partially removed in order to improve the acoustic contact for the elastographic measurements. The cranial and caudal endplates of the segment were then embedded in polymethylmethacrylate (Figure 2), taking care compression tests. The samples were kept in sealed bags at room temperature between tests.

\section{Protocol}

Each sample was tested in compression to obtain its mechanical properties, as described

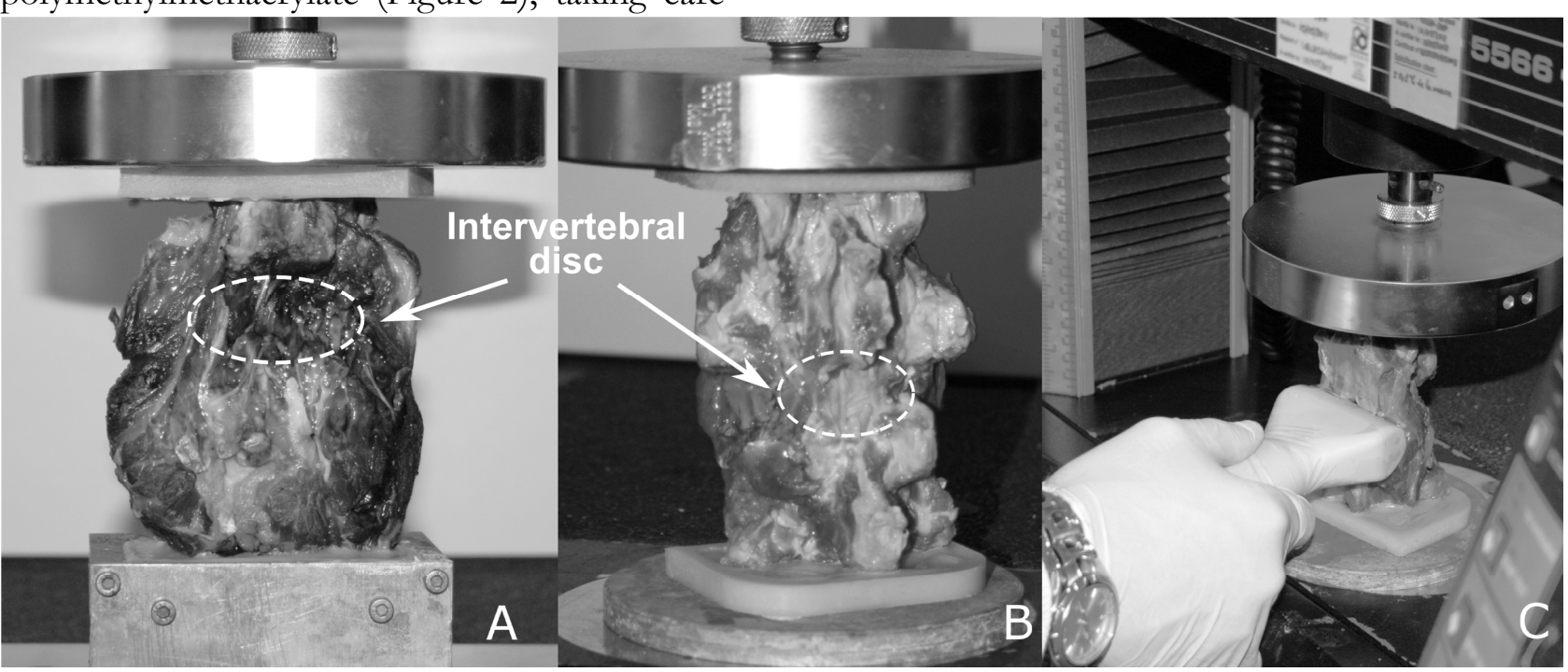

Figure 2 - Example of a prepared sample and measurement setup. Soft tissues in the ventral aspect (A) were partially removed to insure a good acoustic contact while those in the dorsal aspect (B) were completely removed in order to test the mechanical properties of the intervertebral disc alone. The cranial and caudal endplates of the segment were embedded in polymethylmethacrylate to avoid buckling and slipping during the mechanical test. Elastographic measurements (C) were performed with the probe placed transversally in the ventral region of the sample. 
below, which were than compared to elastographic measurements of the IVD. The whole protocol (mechanical testing and elastography) was repeated six times, with thirty minute pauses, in order to evaluate measurement repeatability.

\section{Mechanical tests}

Samples were tested in compression (Instron 5566 with $5 \mathrm{kN}$ load cell, Instron, Massachusetts, USA): after applying a $20 \mathrm{~N}$ preload, four continuous cycles between 0 and $400 \mathrm{~N}$ were performed at constant displacement speed of $0.5 \mathrm{~mm} / \mathrm{min}$; force and displacement were recorded by the testing machine. The first three cycles served as sample preconditioning, as is usually performed in soft tissue testing [40]; preliminary tests showed that this number of cycles was sufficient to produce a repeatable mechanical response. The forcedisplacement curve of the fourth compression was approximated with a multilinear model composed of three line segments (Figure 3), which were fitted to the data by minimizing the root mean squared error. The slopes of the first and third segment approximate the sample's compressive stiffness at rest $\left(K_{0}\right)$ and near the $400 \mathrm{~N}$ load $\left(K_{400}\right)$, respectively (Figure 3 ). Immediately after this fourth cycle, the sample was unloaded and loaded again at $400 \mathrm{~N}$; the position was then held (thus inducing stress

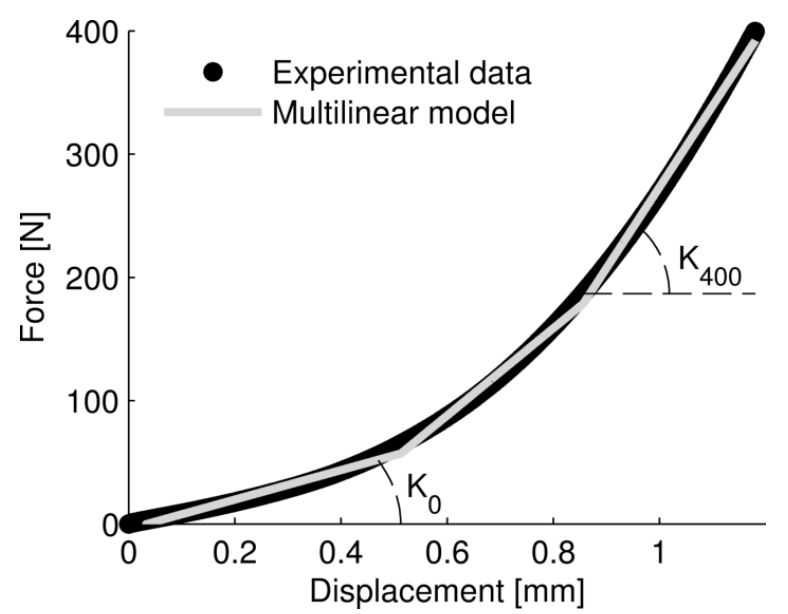

Figure 3 - Example of a characteristic forcedisplacement curve (first test of sample \#1). The experimental data were modelled with a multilinear model; the slope of the first $\left(K_{0}\right)$ and third segment $\left(K_{400}\right)$ correspond to the sample's stiffness at rest and under loading. relaxation) during the acquisition of elastographic images.

\section{Principle of elastographic measurements}

Elastographic images were acquired using a commercial device (Aixplorer, SuperSonic Imagine, France). The ultrasonic probe (SuperLinear SL 15-4, $8 \mathrm{MHz}$ central frequency) was placed transversally on the sample's ventral aspect, at the mid-height of the IVD (Figure 2). The positioning was considered appropriate when the IVD lamellae were clearly visible in the ultrasonographic images (Figure 4). This device creates a Mach cone in the tissue by focusing ultrasound waves at different successive depths [41]; this generates a quasi-plane shear wave in the image plane (i.e. the transverse plane of the disc), propagating parallel to the lamellae with a polarization perpendicular to the lamellae [42]. The local displacements induced by this wave can be observed with ultrafast imaging [43], allowing the evaluation of local shear wave speed (SWS).

\section{Image acquisition protocol}

Ten elastographic images were recorded before the mechanical test (immediately after the $20 \mathrm{~N}$ preload was applied) and ten more during the stress relaxation (starting at $400 \mathrm{~N}$ compression). A region of interest (ROI) was selected in the annulus fibrosus (Figure 4) offline (i.e., after the experiment) and semiautomatically tracked in each image using custom software. The average shear wave speed in the sample at rest $\left(S W S_{0}\right)$ and at $400 \mathrm{~N}$ $\left(S W S_{400}\right)$ was estimated by averaging the mean SWS observed in each ROI $(n=10$ in each condition).

The following relationship exists between SWS and the tissue's shear modulus $(\mu)$ : $S W S=\sqrt{\mu / \rho}$, where $\varrho$ is the tissue's mass density. Assuming a constant mass density of $1100 \mathrm{~kg} / \mathrm{m}^{3}$, an average "acoustic shear modulus" was calculated in the disc's transversal plane and in the direction parallel to the lamellae $\left(\mu_{/}\right)$. 


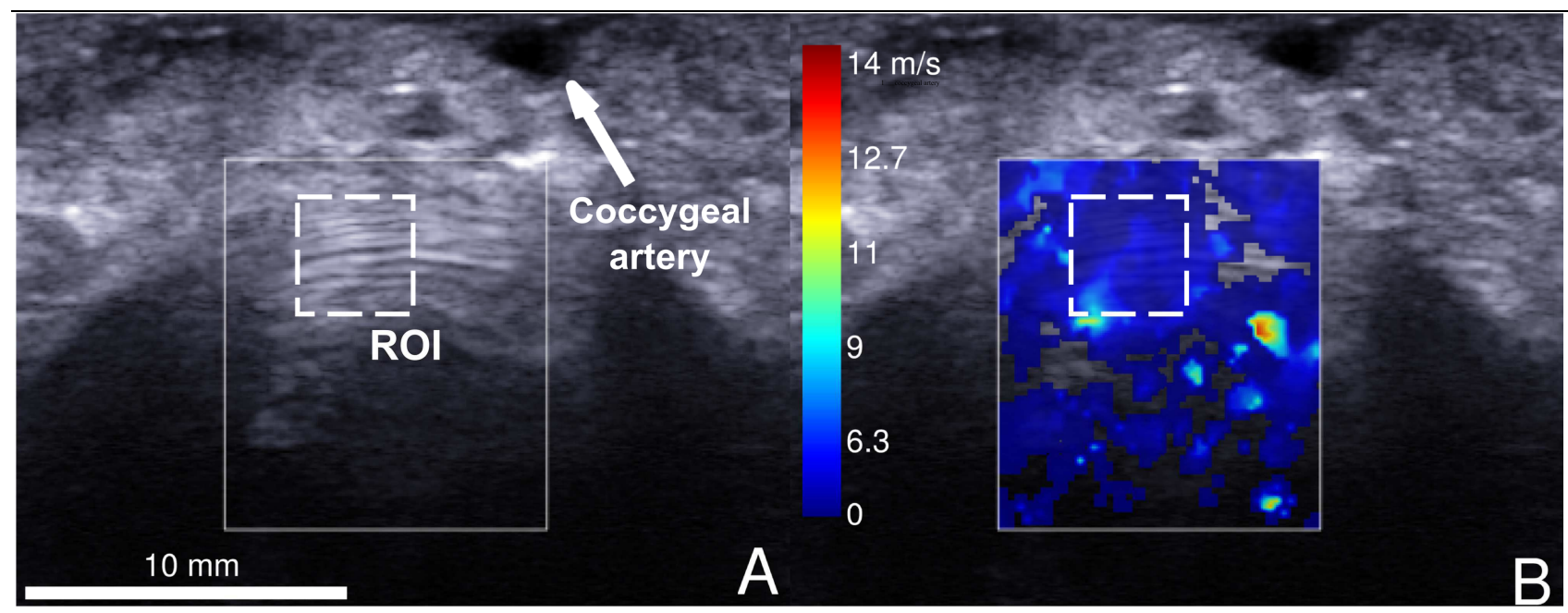

Figure 4 - Characteristic transversal image of intervertebral disc (sample \#1), in ultrasonography (A) and elastography (B). The solid line rectangle is the region where the shear wave speed (SWS) was measured while the dashed line rectangle is the region of interest (ROI), in the annulus fibrosus, where SWS values were retained and averaged. The arrow points to the coccygeal artery which sometimes provoked artefacts in the ultrasonographic image and affected the shear wave propagation. The lateral regions of the disc (left and right in the image) are hypoechoic because ultrasound signals are refracted off its rounded surface.

\section{Geometrical and material properties}

Cross-sectional area (CSA) and thickness of IVDs at rest were evaluated from stereoradiographs. Nine stereocorresponding points were defined on the surfaces of inferior and superior vertebral endplates (Figure 1). This allowed 3D profiling of the endplate surfaces, which was used to evaluate the IVD CSA at rest $\left(C S A_{0}\right.$, the mean cross-section of the two surfaces) and thickness at rest $\left(L_{0}\right.$, the mean point-to-surface distance between surfaces).

Axial strain in the IVD during the compression test was defined as $\varepsilon=\Delta L / L_{0}$, where $\Delta L$ is the displacement as recorded by the testing machine. Instantaneous CSA was evaluated from the axial strain [44] as $C S A=$ $C S A_{0} /(1+\varepsilon)$, with the hypothesis of material incompressibility (i.e., assuming a Poisson's ratio of 0.5 ).

Apparent IVD elastic modulus at rest $\left(E_{0}\right)$ was defined as $E_{0}=K_{0} / C S A_{0} * L_{0}$ while apparent IVD elastic modulus under $400 \mathrm{~N}$ compression was defined as $E_{400}=K_{400} /$ $C S A_{400} * L_{400}$, where $C S A_{400}$ and $L_{400}$ are the average instantaneous CSA and length observed in the third segment of the multilinear approximation (Figure 3).

\section{Statistics}

Repeatability of SWS measurements was assessed according to ISO 5725 while inter-test reliability was evaluated with the intraclass correlation coefficient (ICC); an ICC greater than 0.75 was considered to signify good agreement [45]. Bland-Altman plots were used to present the limits of agreement. Correlations were analysed with Spearman's rank correlation coefficient while differences were analysed with Wilcoxon signed-rank tests; significance was set at 0.05 .

\section{Results}

Five tests out of sixty-six (eleven samples times six tests) had to be discarded because of artefacts in the elastographic images. The multilinear model provided a good approximation to the loading curves, yielding an average root mean square error of $2.2 \pm 0.7$ $\mathrm{N}$. Values of $K, E$ and SWS are given in Table 1. $K_{0}$ and $E_{0}$ were significantly lower than $K_{400}$ and $E_{400}$, respectively. $S W S_{0}$ was significantly lower than $S W S_{400}$ in samples \#2 and \#11, while it was higher in sample \#7 $(p<0.05)$. The global average SWS were the same at rest and at $400 \mathrm{~N}(5.3 \pm 1.0 \mathrm{~m} / \mathrm{s})$. The acoustic shear modulus was $31.9 \pm 10.0 \mathrm{kPa}$. 

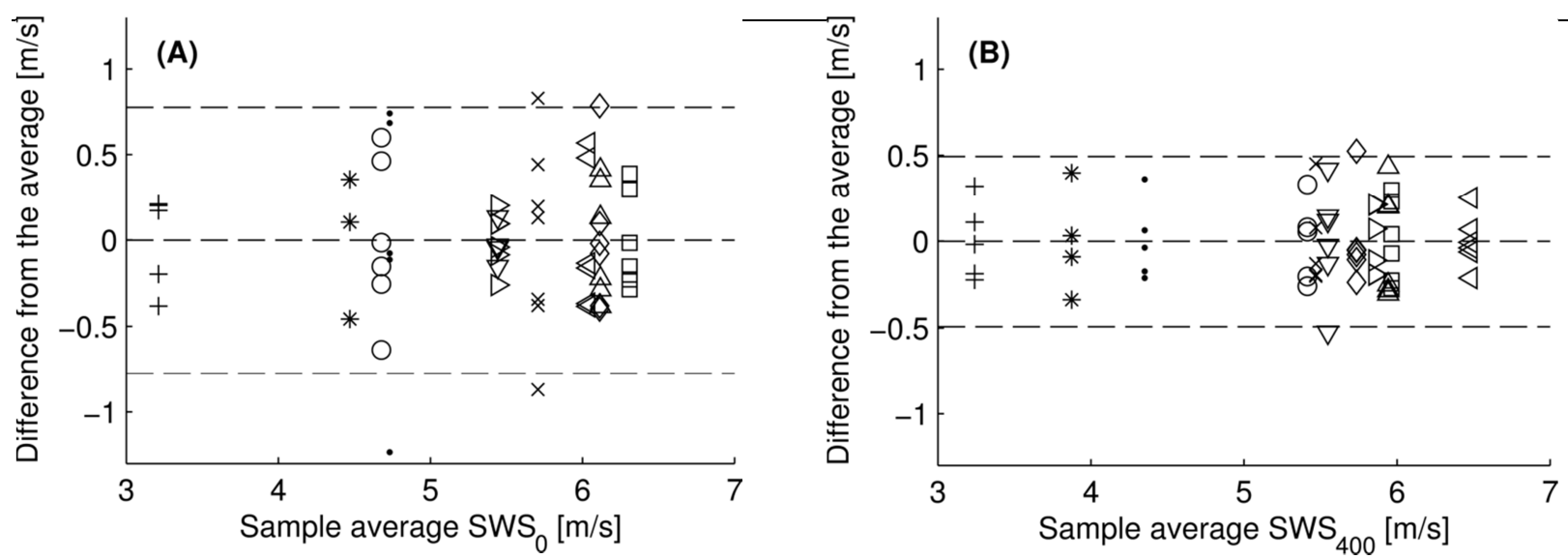

Figure 5 - Bland-Altmann plot of shear wave speed measurements at rest $\left(S W S_{0}\right)$ and at $400 \mathrm{~N}$ $\left(S W S_{400}\right)$. Each symbol represents a sample, while the dashed lines are twice the measurement repeatability.

Repeatability of $S W S_{0}$ was $0.39 \mathrm{~m} / \mathrm{s}$ (corresponding to $7.0 \%$ of global average value) while repeatability of $S W S_{400}$ was 0.25 $\mathrm{m} / \mathrm{s}$ ( $4.7 \%$ of the global average). ICC of $S W S_{0}$ and $S W \mathrm{~S}_{400}$ were 0.96 and 0.99 respectively. The Bland-Altmann plots of SWS measurements are reported in Figure 5.

Correlation between SWS and mechanical properties are reported in Table 2; the strongest correlations were between $\mathrm{SWS}_{400}$ and $\mathrm{K}_{400}$ (Figure 6, Spearman's rho $=0.63, \mathrm{p}<0.05$ ) and between $S W S_{0}$ and both $K_{400}$ (Figure 7, Spearman's rho $=0.64, \mathrm{p}<0.05)$ and $E_{400}$ (Spearman's rho $=0.7, \mathrm{p}<0.05)$.

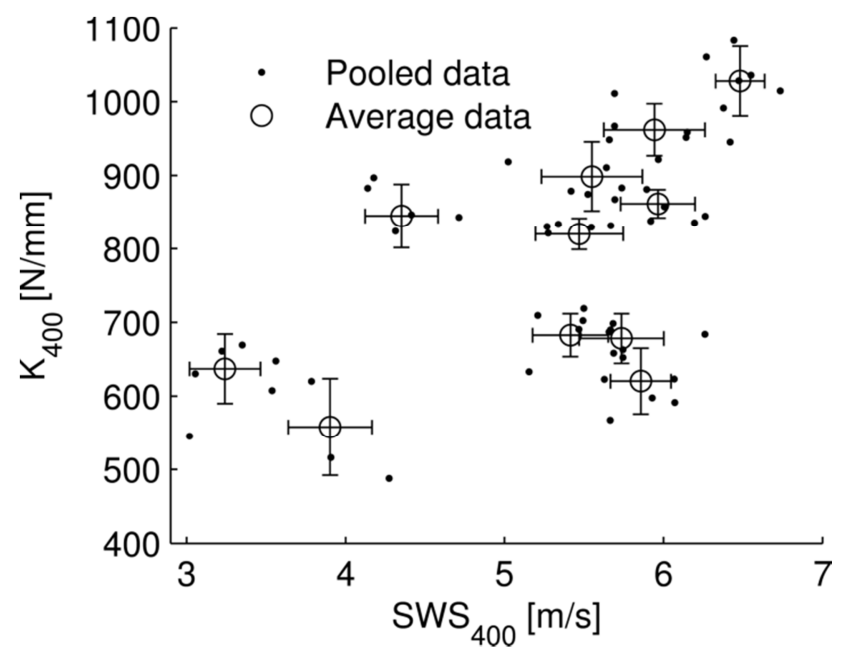

Figure 6 - Relationship between shear wave speed at $400 \mathrm{~N}\left(S W S_{400}\right)$ and intervertebral disc stiffness $\left(K_{400}\right)$; pooled (black dots) and average values (circles, with error bars representing the standard deviations). The correlation was significant (Spearman's rho $=0.63, \mathrm{p}<0.05$ ).

\section{Discussion}

Personalization of tissue mechanical properties through non-invasive means is a challenge. This study explored, for the first time, the feasibility of intervertebral disc mechanical characterization by ultrasound elastography; an in-vitro approach was chosen to assess the reliability of elastography when applied to this tissue.

The acoustic shear modulus of the bovine tail disc annulus fibrosus was evaluated to be $31.9 \pm 10.0 \mathrm{kPa}$. Mass density was assumed to be known and constant to obtain this value; this property, however, might change with disc

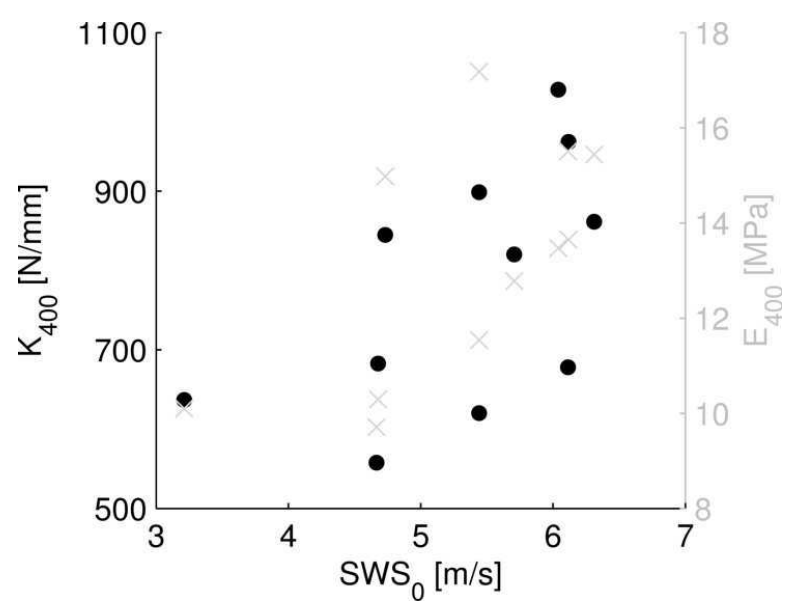

Figure 7 - Relationship of shear wave speed at rest $\left(S W S_{0}\right)$ with intervertebral disc stiffness $\left(K_{400}\right.$, black dots) and with apparent elastic modulus ( $E_{400}$, grey $\mathrm{x}$ symbols) at $400 \mathrm{~N}$. Correlation of $S W S_{0}$ with both variables was significant $(\mathrm{p}<0.05)$. 
Table 1. Geometrical, elastographic and mechanical characteristics of 11 intervertebral discs. Length $(L)$, cross-sectional area (CSA), stiffness $(K)$, apparent elastic modulus $(E)$ and shear wave speed (SWS). Only significant values and tendencies are reported. The 0 and 400 subscripts denote the reference force.

\begin{tabular}{|c|c|c|c|c|c|c|c|c|c|}
\hline Sample & $\begin{array}{l}L_{0} \\
{[\mathrm{~mm}]}\end{array}$ & $\begin{array}{l}C S A_{0} \\
{\left[\mathrm{~mm}^{2}\right]}\end{array}$ & $\begin{array}{l}C S A_{400} \\
{\left[\mathrm{~mm}^{2}\right]}\end{array}$ & $\begin{array}{l}K_{0} \\
{[\mathrm{~N} / \mathrm{mm}]}\end{array}$ & $\begin{array}{l}K_{400} \\
{[\mathrm{~N} / \mathrm{mm}]}\end{array}$ & $\begin{array}{l}E_{0} \\
{[\mathrm{MPa}]}\end{array}$ & $\begin{array}{l}E_{400} \\
{[\mathrm{MPa}]}\end{array}$ & $\begin{array}{l}\mathrm{SWS}_{0} \\
{[\mathrm{~m} / \mathrm{s}]}\end{array}$ & $\begin{array}{l}S W S_{400} \\
{[\mathrm{~m} / \mathrm{s}]}\end{array}$ \\
\hline 1 & 8.1 & 393 & 438 & $360.7 \pm 33.7$ & $636.9 \pm 47.2$ & $7.4 \pm 0.7$ & $10.6 \pm 1.0$ & $3.2 \pm 0.3$ & $3.2 \pm 0.2$ \\
\hline 2 & 6.3 & 344 & 379 & $221.6 \pm 18.3$ & $682.5 \pm 29.1$ & $4.1 \pm 0.3$ & $10.3 \pm 0.5$ & $4.7 \pm 0.5$ & $5.3 \pm 0.4^{*}$ \\
\hline 3 & 8.6 & 393 & 430 & $252.6 \pm 13.7$ & $557.8 \pm 65.8$ & $5.5 \pm 0.3$ & $10.2 \pm 1.4$ & $4.7 \pm 0.4$ & $3.9 \pm 0.3$ \\
\hline 4 & 8.3 & 385 & 425 & $230.2 \pm 18.2$ & $844.8 \pm 43.2$ & $5.0 \pm 0.4$ & $15.0 \pm 0.9$ & $4.7 \pm 0.8$ & $4.4 \pm 0.2$ \\
\hline 5 & 7.1 & 391 & 431 & $363.4 \pm 14.1$ & $820.2 \pm 21.1$ & $6.6 \pm 0.3$ & $12.2 \pm 0.4$ & $5.7 \pm 0.6$ & $5.5 \pm 0.3$ \\
\hline 6 & 7.4 & 357 & 383 & $205.4 \pm 15.5$ & $861.5 \pm 19.3$ & $4.3 \pm 0.3$ & $15.6 \pm 0.4$ & $6.3 \pm 0.3$ & $6.0 \pm 0.2$ \\
\hline 7 & 7.5 & 268 & 297 & $191.5 \pm 10.2$ & $678.1 \pm 33.6$ & $5.4 \pm 0.3$ & $15.5 \pm 0.9$ & $6.1 \pm 0.4$ & $5.7 \pm 0.3^{*}$ \\
\hline 8 & 8.0 & 450 & 504 & $262.3 \pm 7.5$ & $962.1 \pm 35.1$ & $4.7 \pm 0.1$ & $13.6 \pm 0.6$ & $6.1 \pm 0.3$ & $5.9 \pm 0.3$ \\
\hline 9 & 6.9 & 302 & 330 & $261.3 \pm 17$ & $898.7 \pm 47.2$ & $6.0 \pm 0.4$ & $17.1 \pm 1.1$ & $5.4 \pm 0.1$ & $5.5 \pm 0.3$ \\
\hline 10 & 5.9 & 358 & 401 & $383.3 \pm 33.8$ & $1028 \pm 47.3$ & $6.3 \pm 0.6$ & $13.5 \pm 0.8$ & $6.0 \pm 0.4$ & $6.5 \pm 0.2$ \\
\hline 11 & 8.0 & 386 & 408 & $196.4 \pm 0.6$ & $620.2 \pm 44.8$ & $4.1 \pm 0.6$ & $11.5 \pm 0.7$ & $5.4 \pm 0.2$ & $5.9 \pm 0.2^{*}$ \\
\hline $\begin{array}{l}\text { Mean } \\
\pm \text { SD }\end{array}$ & $\begin{array}{l}7.5 \\
\pm 0.9\end{array}$ & $\begin{array}{l}366.1 \\
\pm 49.2\end{array}$ & $\begin{array}{l}402.3 \\
\pm 55.7\end{array}$ & $266.3 \pm$ & $\begin{array}{l}781.0 \\
153.8\end{array}$ & $t_{5,4}+$ & $13.2 \pm 2.4$ & $5.3 \pm$ & $5.3 \pm$ \\
\hline
\end{tabular}

* Significant difference between shear wave speed in unloaded and loaded intervertebral disc $(\mathrm{p}<0.05)$

compression and it might not be homogeneous in the annulus. Still, this acoustic shear modulus is similar to the shear modulus measured by mechanical testing in unloaded human annulus fibrosus $(32.12 \pm 18.4 \mathrm{kPa})[46]$.

Elastography is thus a direct measure of the tissue shear modulus, although values in the literature are often reported in terms of elastic modulus, which is approximated as $E \approx 3 \mu$ with the explicit hypothesis of tissue incompressibility. This approximation is only valid in homogeneous isotropic tissues; more generally, transverse shear modulus, and $a$ fortiori SWS, cannot be used to calculate longitudinal elastic modulus in anisotropic tissues [42]. The annulus fibrosus, where SWS was measured, is a composite material consisting of collagen fibres arranged in concentric lamellae, presenting fibres that run in the same direction within a given lamella but at different angles to those in adjacent lamellae [47]. This gives the annulus fibrosus a nonhomogeneous anisotropic character, which does not allow the application of this approximation: therefore, only wave velocity values were reported in this study. Still, data showed correlations between SWS in the transverse plane and axial stiffness and apparent elastic modulus in loaded IVD (Table 2).

SWS values were expected to increase with the load applied to the IVD, since shear modulus generally increases in loaded soft tissues [46], but the global average remained unchanged at 
$5.3 \mathrm{~m} / \mathrm{s}$ while SWS significantly increased in two samples and decreased in one (Table 1).

Table 2. Spearman's rank correlation coefficient between measured variables: intervertebral disc stiffness $(K)$, apparent elastic modulus $(E)$ and shear wave speed (SWS). The 0 and 400 subscripts denote the reference force.

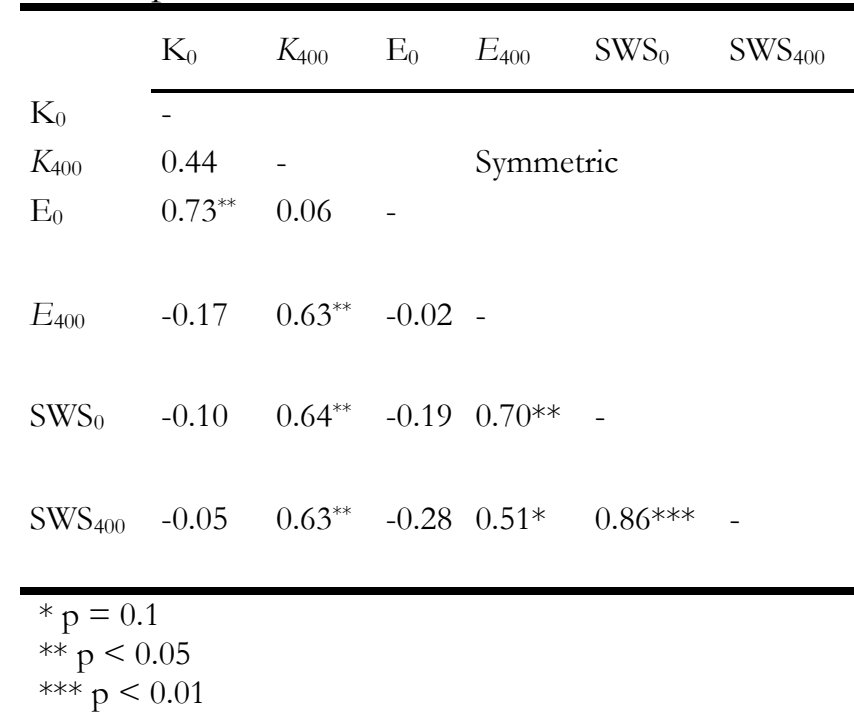

A thorough characterization of the IVD acoustic anisotropy should be performed in order to better understand how compressive loading affects the shear modulus in different planes (and different regions) of the disc. Shear modulus in the direction orthogonal to the lamellae $\left(\mu_{\perp}\right)$, for instance, can be evaluated by measuring the SWS in the direction perpendicular to the lamellae. This could not be done by placing the ROI laterally in the IVD, however, because ultrasound waves do not penetrate in this region which in fact appears hypoechogenic (Figure 4); this is due to the refraction of the waves off the disc's rounded surface and series of lamellae, which prevents imaging of shear wave propagation.

A distinction should be made between the annulus elastic modulus, which is a material property, and the apparent IVD elastic modulus in axial compression which was measured by uniaxial mechanical testing in the present work. The former can be evaluated by applying the approximation $E \approx 3 \mu$ to the previously defined acoustic shear modulus; this yields an elastic modulus for the annulus of $95.8 \pm 30.0$ $\mathrm{kPa}$. This is much lower than the average apparent elastic modulus which was measured by mechanical test $(5.4 \mathrm{MPa}$ in unloaded disc or 13.2 $\mathrm{MPa}$ in loaded disc, Table 1), because the latter depends on the homogenized structural modelling of the disc and is affected by the complex interaction between annulus fibrosus and nucleus pulposus in compression. Apparent material properties and stiffness values, however, are often used in mechanical models of the spine [for instance 48, 49]. More sophisticated mechanical models exist that account for the local and dynamic behaviour of the disc; they could be implemented in further studies to simulate shear wave propagation in the tissue and how it is affected by the mechanical compression.

Race et al. [50] previously tested 16 oxtail IVDs loaded in compression to $0.9 \mathrm{MPa}$ at 0.03 $\mathrm{MPa} / \mathrm{s}$ loading rate, finding an average apparent elastic modulus of $11 \mathrm{MPa}$. This value is similar to the value of $E_{400}$ observed in the present study $(13.2 \pm 2.4 \mathrm{MPa})$, and the testing conditions are comparable as well: the maximal stress and loading rate adopted in this study can be evaluated at $1.0 \mathrm{MPa}(400 \mathrm{~N}$ divided by the average $\left.C S A_{400}\right)$ and $0.02 \mathrm{MPa} / \mathrm{s}$, respectively. The mechanical properties obtained in the present work are of the same order of magnitude as those observed in human vertebrae; for instance, Campana [51] reported a maximal elastic modulus for L1-L2 human IVD of $9.1 \mathrm{MPa}$, and a maximal stiffness of $679 \mathrm{~N} / \mathrm{mm}$ with a compression rate of 800 $\mathrm{N} /$ min (compared with a value of $K_{400}$ of 781.0 $\pm 153.8 \mathrm{~N} / \mathrm{mm}$ and a loading rate of about 390 $\mathrm{N} / \mathrm{min}$ in the present study, in which the displacement rate was imposed). O'Connell et al. [52] reported a stiffness of L1-L2 and L2-L3 segments of $1498 \mathrm{~N} / \mathrm{mm}$, but these authors performed much slower mechanical tests and to a higher maximal load than in the present study $(1 \mathrm{~N} / \mathrm{s}$ up to $2000 \mathrm{~N}$, versus a loading rate of about $6.5 \mathrm{~N} / \mathrm{s}$ in the present study).

The lack of correlation between unloaded IVD mechanical properties $\left(E_{0}\right)$ and $S W S_{0}$ is probably due to the fact that the latter is measured in the annulus fibrosus (Figure 4), while the former are apparent properties of the whole disc. It has been previously demonstrated by progressive denucleation of 
the disc that the mechanical role of the nucleus pulposus is more pronounced in the low force range $[53,54]$, while the stiffness is minimally affected by denucleation at higher loads. SWS was measured in the annulus fibrosus and compared to mechanical parameters $\left(K_{0}\right.$ and $\left.E_{0}\right)$ which were dominated by the behaviour of the nucleus pulposus; hence, the lack of correlation. Conversely, $K_{400}$ and $E_{400}$ were dominated by the mechanical behaviour of the annulus fibrosus, and their correlation with SWS was significant.

Because of its viscoelastic character, thirty minute pauses were necessary to allow recovery of the IVD properties between tests. Van der Veen et al. [55] showed that much longer recovery time was necessary for the disc to attain the initial mechanical properties, but those authors subjected the IVD to $20 \mathrm{~N}$ load during recovery, in order to simulate physiological conditions. Discs were left unloaded during recovery in the present work, and preliminary tests showed that 30 minutes were sufficient to recover the disc's initial stiffness. These pauses might have caused dehydration of the samples, which can affect the IVD mechanical properties [50], although samples were kept in sealed bags during these pauses. Nevertheless, the sample's mechanical properties and SWS values did not drift over time, thus suggesting that dehydration did not significantly affect the tests and confirming that thirty minutes were enough for the IVD to recover. The repeatability of mechanical tests also confirms that samples were not damaged by the relatively large imposed displacements (11\% global average maximal strain).

Elastographic measurements were performed during stress relaxation, starting at $400 \mathrm{~N}$. The measurements lasted between 10 and 20 seconds, and no clear drift in SWS was observed during this relaxation. The effects of viscoelasticity on SWS measurements could be evaluated with longer measurements during stress relaxation or creep.

Five tests out of sixty-six were discarded because of artefacts that appeared in several elastographic images. These artefacts were often due the coccygeal artery, a large blood vessel that runs longitudinally in the ventral aspect of the oxtail, where the elastographic measurements were performed (Figure 4); the absence of blood might have allowed presence of small air pouches in the empty artery, or induced bad acoustic contact between the artery walls, thus affecting ultrasound propagation.

The repeatability of SWS measurements in unloaded and loaded IVD was evaluated to be 0.39 and $0.25 \mathrm{~m} / \mathrm{s}$, respectively, with an excellent test-retest agreement (ICC > 0.9). These values, corresponding to 7.0 and $4.6 \%$ of the average values, are much lower than the observed inter-specimen difference, which were in the range between 3.2 and $6.5 \mathrm{~m} / \mathrm{s}$, confirming that it is possible to discriminate between a stiff IVD in compression and a softer one. Previous reproducibility assessment on phantoms gave results in the same order of magnitude [56], with a reproducibility of 0.82 $\mathrm{kPa}$ (corresponding to $0.5 \mathrm{~m} / \mathrm{s}$ ).

If the findings of this study on animal samples can be confirmed through future studies on human discs, shear wave elastography would be confirmed as a good candidate for non-invasive IVD mechanical characterization

\section{Conclusion}

The aim of the present work was to assess the feasibility of intervertebral disc characterization by elastography. Shear wave speed measurements were found to be repeatable and they were correlated to key mechanical parameters of the disc, such as compressive stiffness and apparent elastic modulus, especially in loaded disc. This measurement validation in an animal sample was a necessary step to open the way to in vivo shear wave speed measurements for noninvasive characterization of human intervertebral disc.

\section{Conflict of interest statement}

Jean-Luc Gennisson is a scientific consultant for SuperSonic Imagine, and Mickael Tanter is cofounder and shareholder of SuperSonic Imagine (Aix-en-Provence, France). The other authors do not have any conflicting financial interests. 


\section{Acknowledgements}

The authors are grateful to the ParisTech BiomecAM chair program on subject-specific musculoskeletal modelling for funding (with the support of Proteor, ParisTech and Yves Cotrel Foundations).

\section{References}

1. Lafage V, Dubousset J, Lavaste F, Skalli W. 3D finite element simulation of Cotrel-Dubousset correction. Computer aided surgery : official journal of the International Society for Computer Aided Surgery. 2004;9(1-2):17-25. Epub 2005/03/29.

2. Lafon Y, Lafage V, Dubousset J, Skalli W. Intraoperative three-dimensional correction during rod rotation technique. Spine. 2009;34(5):512-9. Epub 2009/02/28.

3. Aubin CE, Labelle H, Chevrefils C, Desroches G, Clin J, Eng AB. Preoperative planning simulator for spinal deformity surgeries. Spine. 2008;33(20):2143-52. Epub 2008/09/17.

4. Drevelle X, Lafon Y, Ebermeyer E, Courtois I, Dubousset J, Skalli W. Analysis of Idiopathic Scoliosis Progression by Using Numerical Simulation. Spine. 2010;35(10):E407-E12.

5. Villemure I, Aubin CE, Dansereau J, Labelle H. Simulation of progressive deformities in adolescent idiopathic scoliosis using a biomechanical model integrating vertebral growth modulation. J Biomech Eng. 2002;124(6):784-90. Epub 2003/02/25.

6. Kurowski P, Kubo A. The Relationship of Degeneration of the Intervertebral Disc to Mechanical Loading Conditions on Lumbar Vertebrae. Spine. 1986;11(7):726-31.

7. Ruberté LM, Natarajan RN, Andersson GBJ. Influence of single-level lumbar degenerative disc disease on the behavior of the adjacent segments-A finite element model study. $J$ Biomech. 2009;42(3):341-8.

8. Rohlmann A, Zander T, Schmidt H, Wilke H-J, Bergmann G. Analysis of the influence of disc degeneration on the mechanical behaviour of a lumbar motion segment using the finite element method. J Biomech. 2006;39(13):2484-90.

9. Tropiano P, Thollon L, Arnoux PJ, Huang RC, Kayvantash K, Poitout DG, et al. Using a finite element model to evaluate human injuries application to the HUMOS model in whiplash situation. Spine. 2004;29(16):1709-16.

10. Neal ML, Kerckhoffs R. Current progress in patient-specific modeling. Brief Bioinform. 2010;11(1):111-26. Epub 2009/12/04.

11. Humbert L, De Guise JA, Aubert B, Godbout B, Skalli W. 3D reconstruction of the spine from biplanar X-rays using parametric models based on transversal and longitudinal inferences. Med Eng Phys. 2009;31(6):681-7. Epub 2009/02/24.

12. Jolivet E, Sandoz B, Laporte S, Mitton D, Skalli W. Fast 3D reconstruction of the rib cage from biplanar radiographs. Med Biol Eng Comput. 2010;48(8):821-8.

13. Dworzak J, Lamecker H, Berg J, Klinder T, Lorenz C, Kainmüller D, et al. 3D reconstruction of the human rib cage from $2 \mathrm{D}$ projection images using a statistical shape model. Int J CARS. 2010;5(2):111-24.

14. Mitton D, Landry C, Véron S, Skalli W, Lavaste F, Guise JA. 3D reconstruction method from biplanar radiography using non-stereocorresponding points and elastic deformable meshes. Med Biol Eng Comput. 2000;38(2):133-9. 
15. Benameur S, Mignotte M, Labelle H, De Guise JA. A hierarchical statistical modeling approach for the unsupervised 3-D biplanar reconstruction of the scoliotic spine. IEEE Trans Biomed Eng. 2005;52(12):2041-57. Epub 2005/12/22.

16. Tanaka N, An HS, Lim T-H, Fujiwara A, Jeon C-H, Haughton VM. The relationship between disc degeneration and flexibility of the lumbar spine. The Spine Journal. 2001;1(1):47-56.

17. Stokes IA, Wilder DG, Frymoyer JW, Pope MH. Assessment of patients with low-back pain by biplanar radiographic measurement of intervertebral motion. Spine. 1981;6(3):233-40. Epub 1981/05/01.

18. Polly DW, Jr., Sturm PF. Traction versus supine side bending. Which technique best determines curve flexibility? Spine. 1998;23(7):804-8. Epub 1998/05/01.

19. Matsumoto T, Kitahara H, Minami S, Takahashi K, Yamagata M, Moriya H, et al. Flexibility in the scoliotic spine: three-dimensional analysis. J Spinal Disorders. 1997;10(2):125-31. Epub 1997/04/01.

20. Petit Y, Aubin CE, Labelle H. Patient-specific mechanical properties of a flexible multi-body model of the scoliotic spine. Med Biol Eng Comput. 2004;42(1):55-60. Epub 2004/02/24.

21. Lafon Y, Lafage V, Steib JP, Dubousset J, Skalli W. In vivo distribution of spinal intervertebral stiffness based on clinical flexibility tests. Spine. 2010;35(2):186-93. Epub 2010/01/19.

22. Little JP, Adam C. Towards determining soft tissue properties for modelling spine surgery: current progress and challenges. Med Biol Eng Comput. 2012;50(2):199-209. Epub 2011/12/27.

23. Reutlinger C, Hasler C, Scheffler K, Buchler P. Intraoperative determination of the loaddisplacement behavior of scoliotic spinal motion segments: preliminary clinical results. Eur Spine J. 2012;21 Suppl 6:S860-7. Epub 2012/02/09.

24. Campana S, Charpail E, de Guise JA, Rillardon L, Skalli W, Mitton D. Relationships between viscoelastic properties of lumbar intervertebral disc and degeneration grade assessed by MRI. $J$ Mech Behav Biomed Mater. 2011;4(4):593-9.

25. Périé D, Iatridis JC, Demers CN, Goswami T, Beaudoin G, Mwale F, et al. Assessment of compressive modulus, hydraulic permeability and matrix content of trypsin-treated nucleus pulposus using quantitative MRI. J Biomech. 2006;39(8):1392-400.

26. Mwale F, Demers CN, Michalek AJ, Beaudoin G, Goswami T, Beckman L, et al. Evaluation of quantitative magnetic resonance imaging, biochemical and mechanical properties of trypsintreated intervertebral discs under physiological compression loading. J Magn Reson Imaging. 2008;27(3):563-73. Epub 2008/01/26.

27. Recuerda M, Perie D, Gilbert G, Beaudoin G. Assessment of mechanical properties of isolated bovine intervertebral discs from multi-parametric magnetic resonance imaging. $B M C$ Musculoskeletal Disorders. 2012;13(1):195.

28. Perie D, Korda D, Iatridis JC. Confined compression experiments on bovine nucleus pulposus and annulus fibrosus: sensitivity of the experiment in the determination of compressive modulus and hydraulic permeability. J Biomech. 2005;38(11):2164-71. Epub 2005/09/13.

29. Recuerda M, Cote SP, Villemure I, Preie D. Influence of experimental protocols on the mechanical properties of the intervertebral disc in unconfined compression. $J$ Biomech Eng. 2011;133(7):071006. Epub 2011/08/10.

30. Schmidt H, Galbusera F, Rohlmann A, Shirazi-Adl A. What have we learned from finite element model studies of lumbar intervertebral discs in the past four decades? J Biomech. 2013;46(14):234255. 
31. Ophir J, Cespedes I, Ponnekanti H, Yazdi Y, Li X. Elastography: a quantitative method for imaging the elasticity of biological tissues. Ultrason Imaging. 1991;13(2):111-34. Epub 1991/04/01.

32. Tanter M, Bercoff J, Athanasiou A, Deffieux T, Gennisson J-L, Montaldo G, et al. Quantitative Assessment of Breast Lesion Viscoelasticity: Initial Clinical Results Using Supersonic Shear Imaging. Ultrasound Med Biol. 2008;34(9):1373-86.

33. Gennisson JL, Deffieux T, Mace E, Montaldo G, Fink M, Tanter M. Viscoelastic and anisotropic mechanical properties of in vivo muscle tissue assessed by supersonic shear imaging. Ultrasound Med Biol. 2010;36(5):789-801. Epub 2010/04/28.

34. Athanasiou A, Tardivon A, Tanter M, Sigal-Zafrani B, Bercoff J, Deffieux T, et al. Breast lesions: quantitative elastography with supersonic shear imaging--preliminary results. Radiology. 2010;256(1):297-303. Epub 2010/05/28.

35. Ferraioli G, Tinelli C, Dal Bello B, Zicchetti M, Filice G, Filice C. Accuracy of real-time shear wave elastography for assessing liver fibrosis in chronic hepatitis C: a pilot study. Hepatology. 2012;56(6):2125-33. Epub 2012/07/07.

36. Bavu É, Gennisson J-L, Couade M, Bercoff J, Mallet V, Fink M, et al. Noninvasive In Vivo Liver Fibrosis Evaluation Using Supersonic Shear Imaging: A Clinical Study on 113 Hepatitis C Virus Patients. Ultrasound Med Biol. 2011;37(9):1361-73.

37. Arda K, Ciledag N, Aktas E, Arrbas BK, Köse K. Quantitative Assessment of Normal SoftTissue Elasticity Using Shear-Wave Ultrasound Elastography. American Journal of Roentgenology. 2011;197(3):532-6.

38. Gennisson JL, Grenier N, Hubrecht R, Couzy L, Delmas Y, Derieppe M, et al., editors. Multiwave technology introducing shear wave elastography of the kidney: Pre-clinical study on a kidney fibrosis model and clinical feasibility study on 49 human renal transplants. IEEE International Ultrasonics Symposium; 2010 11-14 Oct. 2010; San Diego (CA), USA.

39. Gennisson JL, Muller M, Ami O, Kohl V, Gabor P, Musset D, et al., editors. Shear wave elastography in obstetrics: Quantification of cervix elasticity and uterine contraction. IEEE International Ultrasonics Symposium; 2011 18-21 Oct. 2011; Orlando (FL), USA.

40. Fung YC, Skalak R. Biomechanics: Mechanical Properties of Living Tissues. J Biomech Eng. 1981;103(4):231-98.

41. Bercoff J, Tanter M, Fink M. Sonic boom in soft materials: The elastic Cerenkov effect. Applied Physics Letters. 2004;84(12):2202.

42. Royer D, Gennisson JL, Deffieux T, Tanter M. On the elasticity of transverse isotropic soft tissues (L). J Acoust Soc Am. 2011;129(5):2757-60. Epub 2011/05/17.

43. Bercoff J, Tanter M, Fink M. Supersonic shear imaging: a new technique for soft tissue elasticity mapping. IEEE Trans Ultrason Ferroelectr Freq Control. 2004;51(4):396-409. Epub 2004/05/14.

44. Vergari C, Pourcelot P, Holden L, Ravary-Plumioën B, Gerard G, Laugier P, et al. True stress and Poisson's ratio of tendons during loading. J Biomech. 2011;44(4):719-24.

45. Lee J, Koh D, Ong CN. Statistical evaluation of agreement between two methods for measuring a quantitative variable. Computers in Biology and Medicine. 1989;19(1):61-70.

46. Fujita Y, Wagner DR, Biviji AA, Duncan NA, Lotz JC. Anisotropic shear behavior of the annulus fibrosus: effect of harvest site and tissue prestrain. Med Eng Phys. 2000;22(5):349-57. Epub 2000/12/21.

47. Marchand F, Ahmed AM. Investigation of the laminate structure of lumbar disc anulus fibrosus. Spine. 1990;15(5):402-10. Epub 1990/05/01. 
48. Descrimes JL, Aubin CE, Skalli W, Zeller R, Danserau J, Lavaste F. Introduction des facettes articulaires dans une modélisation par éléments finis de la colonne vertébrale et du thorax scoliotique : aspects mécaniques. Rachis. 1995;7(6):301-14.

49. Clin J, Aubin C-E, Parent S, Sangole A, Labelle H. Comparison of the biomechanical 3D efficiency of different brace designs for the treatment of scoliosis using a finite element model. Eur Spine J. 2010;19(7):1169-78.

50. Race A, Broom ND, Robertson P. Effect of loading rate and hydration on the mechanical properties of the disc. Spine. 2000;25(6):662-9. Epub 2000/04/07.

51. Campana S. Evaluation des relations entre propriétés biomécaniques et imagerie : étude in vitro du disque intervertébral. Paris: Arts et Métiers ParisTech; 2004.

52. O'Connell GD, Jacobs NT, Sen S, Vresilovic EJ, Elliott DM. Axial creep loading and unloaded recovery of the human intervertebral disc and the effect of degeneration. J Mech Behav Biomed Mater. 2011;4(7):933-42. Epub 2011/07/26.

53. Cannella M, Arthur A, Allen S, Keane M, Joshi A, Vresilovic E, et al. The role of the nucleus pulposus in neutral zone human lumbar intervertebral disc mechanics. $J$ Biomech. 2008;41(10):2104-11. Epub 2008/06/24.

54. Shea M, Takeuchi TY, Wittenberg RH, White AA, 3rd, Hayes WC. A comparison of the effects of automated percutaneous diskectomy and conventional diskectomy on intradiscal pressure, disk geometry, and stiffness. J Spinal Disorders. 1994;7(4):317-25. Epub 1994/08/01.

55. Van der Veen AJ, van Dieen JH, Nadort A, Stam B, Smit TH. Intervertebral disc recovery after dynamic or static loading in vitro: is there a role for the endplate? J Biomech. 2007;40(10):2230-5. Epub 2006/12/22.

56. Mun HS, Choi SH, Kook SH, Choi Y, Jeong WK, Kim Y. Validation of intra- and interobserver reproducibility of shearwave elastography: Phantom study. Ultrasonics. 2013;53(5):1039-43. 